\title{
VIGENCIA DE LA LEY ITALIANA EN EL ESTADO DE LA CIUDAD DEL VATICANO
}

\author{
ITALIAN LAW EFFECTS IN THE VATICAN CITY
}

\section{JOHN RANSON GARCÍA ${ }^{1}$}

\section{INTRODUCCIÓN}

Se sostiene, casi sin discusión por la mayoría de la doctrina, que la Santa Sede es un sujeto de Derecho Internacional no solo por su primado espiritual universal como institución suprema de la Iglesia Católica, sino que, ante todo, en virtud de sus poderes temporales y como soberano del Estado de la Ciudad del Vaticano, correspondiéndole y poseyendo, en consecuencia, todos los derechos y atributos propios de tales sujetos.

Sin embargo, y pese a lo anterior, se ha suscitado en Italia un agitado debate mediático respecto del cambio del orden de precedencia del ordenamiento jurídico interno de dicho país dentro de las fuentes del derecho del Estado de la Ciudad del Vaticano, cuando la Santa Sede, precisamente utilizando esa misma personalidad y capacidad jurídica, ha procedido a modificar su propia normativa interna, promulgando la nueva Ley sobre las Fuentes del Derecho, continuando, según las palabras del Papa Benedicto XVI, "con la adecuación de la normativa del Estado de la Ciudad del Vaticano", iniciada en el año 2000 con la publicación de la Ley Fundamental promulgada el 26 de noviembre de ese mismo año.

Este es el tema que pretendemos analizar en este artículo, de modo tal de responder la interrogante de si la Santa Sede ha modificado de alguna manera y en forma unilateral los Acuerdos de Letrán, al efectuar tal adecuación a su normativa interna. Para tal efecto se procederá, primeramente, a un breve análisis

${ }^{1}$ Licenciado en Ciencias Jurídicas Pontificia Universidad Católica de Valparaíso, Magíster en Derecho Internacional, Profesor U. de los Andes y U. Central de Chile. histórico de cómo se llegó en el año 1929 a la firma de los citados Acuerdos por parte del Reino de Italia y la Santa Sede, para posteriormente estudiar, brevemente, la Ley Fundamental de la Ciudad del Vaticano, como la Ley sobre las Fuentes del Derecho, cada una con sus respectivas modificaciones.

\section{ANTECEDENTES HISTÓRICOS}

Hasta el año 1870 el Sumo Pontífice no era solamente el Jefe Supremo de la Iglesia Católica, sino también el soberano del Estado Pontificio. Tenía en consecuencia dos poderes: un Poder Temporal, la soberanía sobre el Estado Pontificio, y un Poder Espiritual, que se extendía a todas las comunidades católicas del mundo. En consecuencia los papas sostenían hasta esa fecha que, para el cumplimiento de su misión espiritual de la Iglesia, era garantía indispensable la existencia del Poder Temporal.

Por otro lado, el nacimiento del Reino de Italia se va a lograr a través de una larga y difícil gestación, en la cual hay que tener presente grandes acontecimientos que van marcando los hitos de este camino. Desde antes del Renacimiento se manifiesta el ansia del pueblo italiano de constituir una nación y no un conjunto de Estados independientes; es así como César Borgia luchará, en vano, para hacer realidad este anhelo que dormita durante años en el alma italiana, hasta que los ejércitos de Napoleón vuelven a llamar a la unidad racial y política a los peninsulares con la fuerza de los principios nacionalistas que se esparcen a través de toda Europa.

Alrededor del año 1850, Piamonte hace suyo el movimiento unitario italiano que pide a Roma como capital y en donde la incorpora- 
ción del Estado Pontificio al Reino de Italia fue uno de los puntos del Programa del gran político Cavour. Es así como, en el año 1859, Víctor Manuel II, camino de la unidad italiana, se apodera de la Romaña y de Bolonia, que pertenecían a los dominios pontificios. Dos años después, el 17 de marzo de 1861, este adopta para sí y para sus descendientes el título de Rey de Italia, y con ello pierden los sucesores de San Pedro parte de sus Estados que tenían su origen en los tiempos carlovingios. El 27 de marzo de 1861, diez días después de la proclamación de Víctor Manuel de Saboya como Rey de Italia, el Parlamento italiano vota casi por unanimidad una orden del día confiriendo a Cavour su confianza para lograr la unión de Roma a Italia, capital aclamada por la opinión nacional.

Austria, potencia vecina, y cuya presencia militar en la península era recurrente, procede a invadir Lombardía y Venecia, pues de acuerdo con la política de Metternich el régimen absolutista en los reinos y ducados italianos estaban en la línea de los intereses austriacos, lo que llevó a Francia a intervenir para contrarrestar la influencia de los Hasburgos.

Francia, en tanto, tratando de mantener la independencia del ahora empequeñecido Estado papal, refuerza sus ejércitos en la Ciudad Eterna y firma con Italia en el año 1864 la Convención de Saint-Cloud, en la que el recién creado Reino se compromete a no atacar y a defender al Pontífice de cualquier agresión externa y, por su parte, Francia a evacuar en el período de dos años a sus tropas, para así permitir que se reorganice el ejército papal. Sin embargo, esta Convención no entraría en vigor sino hasta que el Rey de Italia no hubiere elegido como residencia y capital otra ciudad distinta a la de Roma, condición que se cumple cuando, finalmente, se prefiere a Florencia como sede del Gobierno italiano. En el año 1866, Francia, por su parte, da cumplimiento a la Convención de Saint-Cloud y el último soldado francés sale de Roma; sin embargo, sería por poco tiempo, ya que un año después, en 1867, las divisiones galas deben volver a apoyar al ejército pontificio en contra de las fuerzas italianas, que se encontraban a tan solo veinte kilómetros de Roma.
El ejército italiano, en tanto, no puso mayor resistencia retirándose a medida que las tropas francesas tomaban posesión. Sin embargo, Francia, deseosa de resolver definitivamente este problema, propone a las potencias europeas celebrar una reunión en París, tomando como base la Convención de Saint-Cloud, reunión que fracasa estrepitosamente ya que solamente acude Austria.

Producto de las guerras de la unificación alemana las tropas francesas deben retirarse de Roma, y esta vez, frente al avance de las fuerzas enviadas por el Rey Víctor Manuel, quien con el pretexto de defender la Santa Sede y las provincias gobernadas por su Santidad llega hasta las puertas de Roma, violando flagrantemente los principios más elementales del Derecho Internacional al cruzar la frontera pontificia el día 11 de septiembre de 1870 .

Tras la derrota del ejército papal se verifica en Roma, el día 2 de octubre del año 1870 , un plebiscito que fue favorable a la anexión de dicha ciudad al Reino de Italia, la que fue incorporada por Real Decreto del 9 de octubre de 1870; sin perjuicio de lo anterior, los vencedores, por respeto a la persona del Papa Pío IX, no entraron a los palacios vaticanos, pudiéndose afirmar que el Estado Vaticano continuó existiendo en aquel reducido territorio en que no fue materialmente sustituida su autoridad por la italiana, manteniéndose, asimismo, en forma inalterable su derecho de legación activo y pasivo, celebrando concordatos; reconociendo nuevos Estados; actuando como mediador en algunas controversias y considerando al Papa como jefe de un Estado reconocido como sujeto de Derecho Internacional.

El Gobierno italiano con el propósito de tranquilizar a la opinión Católica universal, presenta al Parlamento italiano, el día 13 de mayo de 1871, un proyecto que daría origen a la "Ley de Garantías sobre las Prorrogativas del Soberano Pontífice y de la Santa Sede y sobre las Relaciones del Estado con la Iglesia".

Esta Ley confería al Papa los derechos y honores de un soberano, asimismo, reconocía a los palacios papales su extraterritorialidad y le otorgaba al Sumo Pontífice una suma de dinero anual. Como señala Joaquín Rodríguez 
de Cortázar ${ }^{2}$ al analizar la Cuestión Romana, "las tentativas de acercamiento que inicia el Gobierno italiano con la Ley de Garantías, no serán jamás interrumpidas". Durante el Pontificado de Pío XI, con ocasión de la visita del Rey de España, Alfonso XIII, en noviembre del año 1923, este fue huésped oficial del Rey de Italia, pero también fue recibido oficialmente por el Papa. En aquella ocasión el diario L'Osservatore Romano, en su publicación del 25 de noviembre de ese mismo año, recuerda en una nota los términos de la Encíclica Pacem dei Munus, en la que Benedicto XV autorizaba la visita de los soberanos católicos a los Reyes de Italia, renovándose en el citado artículo las protestas de la Santa Sede de 1870, afirmando que nada había cambiado.

\section{LOS ACUERDOS DE LETRÁN DEL AÑO 1929}

Los Acuerdos de Letrán, firmados el 11 de febrero de 1929, por Benito Mussolini y el Cardenal Pedro Gasparri, como plenipotenciarios de Víctor Manuel III y Pío XI, respectivamente, y ratificados cuatro meses más tarde, el 7 de junio, pusieron término a "la Cuestión Romana” surgida en el año 1870 con la anexión de Roma al reino de Italia bajo la dinastía de la Casa de Saboya, normalizándose las relaciones entre la Santa Sede e Italia.

Estos Acuerdos tienen el carácter de bilaterales y fueron recogidos en la nueva Constitución italiana de 1947. Los Acuerdos de Letrán son tres: un Tratado Político, relacionado con las nuevas garantías de independencia pontificia; un Concordato relativo al régimen eclesiástico; y una Convención Financiera, para la regulación de los créditos que la Santa Sede hacía valer en razón de las confiscaciones sufridas por parte del Gobierno italiano.

El más importante de estos Acuerdos es el Tratado de Letrán, el que reconoce a la Santa Sede su personalidad internacional preexistente, al tiempo que da origen a la creación de un nuevo sujeto internacional, cual es el Estado de la Ciudad del Vaticano; ello resulta evi-

\footnotetext{
${ }^{2}$ Rodríguez de Cortázar (1924) p. 2.
}

dente, toda vez que como señala el profesor Hugo Llanos Mancilla en su obra Teoría y Práctica del Derecho Internacional Público ${ }^{3}$, resulta "totalmente inadmisible mantener que fuera el propio Estado de la Ciudad del Vaticano el que pactara, pues este aún no había nacido".

Entre las disposiciones más significativas del Tratado de Letrán podemos citar las siguientes;

a) Italia reconoce la soberanía de la Santa Sede en el dominio internacional, como un atributo inherente a su naturaleza, en conformidad con su tradición y con las exigencias de su misión en el mundo.

b) Igualmente, Italia reconoce a la Santa Sede el derecho de legación activo y pasivo, obligándose ambas partes a establecer relaciones diplomáticas. En el hecho, la Santa Sede mantiene misiones diplomáticas en muchos países. Los jefes de misión de la Santa Sede que tienen rango más alto son los nuncios. Respecto de los Estados con los que la Santa Sede no mantiene relaciones diplomáticas, esta envía un delegado apostólico, el cual es representante del Papa ante la Iglesia local.

c) En el artículo $4^{\circ}$ se señala que "la soberanía y la jurisdicción exclusiva que Italia reconoce a la Santa Sede sobre la Ciudad del Vaticano, implica que no pueda practicarse en ella injerencia alguna por parte del Gobierno italiano y que allí no exista otra autoridad que la de la Santa Sede”, agregando en el siguiente artículo que, "para la ejecución de lo que se establece en el artículo anterior, antes de entrar en vigor el presente Tratado, el territorio que constituye la Ciudad del Vaticano deberá quedar libre, por cuenta del Gobierno italiano, de toda carga y de ocupadores eventuales".

De esta forma el Estado del Vaticano se configuró con una superficie exigua de 44 hectáreas y como lo recordara don Santiago Benadava $^{4}$ fue el Papa Pablo VI quien en un discurso pronunciado ante la Asamblea General de las Naciones Unidas, expresó que "el Papa no

\footnotetext{
${ }^{3}$ Llanos Mancilla (1980) p. 38.

${ }^{4}$ Benadava (1976) p. 124.
} 
$202 \square \frac{\text { Revista Chilena de Derecho, vol. } 36 \text { Nº 1, pp. 199-204 [2009] }}{\text { Ensayos y Crónicas }}$

está investido sino de una minúscula y cuasi simbólica soberanía temporal: el mínimo necesario para ser libre de ejercer su misión espiritual y para asegurar a aquellos que tratan con él que es independiente de toda soberanía de este mundo".

\section{MODIFICACIÓN AL TRATADO DE LETRÁN DEL AÑO 1984}

En el año 1984 tiene lugar en Italia la modificación del sistema constitucional, el cual fue acompañado de la revisión de los Acuerdos de Letrán. Es así como el 18 de febrero del citado año 1984 se anuncia, con toda solemnidad por la Presidencia del Consejo de Ministros en la Sala Giulio Romano de Villa Madama, que entre la Santa Sede e Italia se firmaría un acuerdo, el que aportaría modificaciones al Concordato Lateranense.

Respecto de esta modificación, se ha estimado que tres serían los presupuestos que las habrían motivado, los cuales vienen enunciados en el preámbulo del nuevo Acuerdo. El primero, que constataba una realidad en ebullición que era la transformación social, política y religiosa realzada por los acontecimientos ocurridos en Italia y por las consecuencias derivadas del Vaticano II en la Iglesia. El segundo, decía relación con la incidencia de los principios tanto de la Constitución italiana como de las declaraciones conciliares sobre la libertad religiosa y las relaciones entre la Iglesia y el Estado, así como de la nueva codificación del año 1983. El tercer presupuesto, que para los efectos de este estudio resulta ser el más importante, decía relación con la exigencia del común acuerdo para modificar los Pactos de Letrán, el cual marca una vía normativa a seguir.

La razón principal del tercer presupuesto estribaría en que este incidía claramente en las coordenadas que enmarcaban el régimen precedente, a saber, la Constitución Republicana del año 1947 y el régimen Lateranense del año 1929, el cual venía fijado fundamentalmente por los tres Pactos de Letrán, en donde la vigencia de estos estaba -y sigue estando- garantizada en el artículo $7^{\circ}$ de la Constitución italiana. Ahora bien, la perma- nencia de las normas vigentes con anterioridad al nuevo movimiento político italiano de democracia y a la actual Constitución republicana planteaba una serie de cuestiones de mutua correlación. La dificultad de resolverlas se agudizaba toda vez que la regulación precedente pertenecía al orden internacional, cuales eran los Pactos de Letrán. Nada extraño si se tiene en cuenta la gran disparidad de épocas en que habían nacido los Pactos y se había promulgado la Constitución. Un contraste de principios y disposiciones parecía, a primera vista, previsiblemente inevitable.

Para llegar a una solución airosa en esta materia, se mantuvieron dos principios permanentes por ser irrenunciables y se procedió a innovar un principio que hasta aquel momento era considerado fundamental. Por ello se mantuvo el principio de que el Estado y la Iglesia Católica son independientes y soberano cada uno en su orden, tal como se venía y se sigue enunciando en el artículo $7^{\circ}$ de la Constitución italiana, e igualmente el principio complementario relativo a la recíproca colaboración en la promoción del hombre y el bien del país. A la par, empero, se introdujo un nuevo principio innovador, el de la aconfesionalidad del Estado, al considerarse sin vigor en adelante el principio anteriormente mencionado en los Pactos Lateranenses, de que la Religión Católica era la única del Estado italiano.

En consecuencia, puede estimarse razonablemente que el Acuerdo de Modificación del Concordato de Letrán ha merecido una muy positiva valoración final, ya que conforme a los principios enunciados precedentemente, se fueron desarrollando y solventando las cuestiones concretas que se presentaban relativas a temas tales como la libertad organizativa de la Iglesia; el matrimonio; la enseñanza; la asistencia espiritual y el patrimonio cultural, entre otros.

En efecto, desde la perspectiva institucional italiana se da entrada por él a un nuevo sistema Constitucional político-religioso: el de la aconfesionalidad del Estado. Desde la perspectiva concordataria, se subroga el Concordato de Letrán por un acuerdo plenamente postconciliar. 
Ley sobre las Fuentes del Derecho del Estado de la Ciudad del Vaticano del 7 de junio de 1929 y su modificación del año 2008.

El Estado del Vaticano posee un ordenamiento autónomo dirigido a tutelar y llevar a cabo los fines propios de la Santa Sede, de esta forma una serie de leyes de rango fundamental conocidas como Acta Apostolicae Sedis, se ocupan de los aspectos constitucionales, fuentes de Derecho, ciudadanía, ordenación administrativa, regulación económica, comercial y profesional y seguridad pública.

En la letra a) del artículo $1^{\circ}$ de la Ley de fecha 7 de junio de 1929, se establecen como fuentes principales del Derecho "el Codex iuris canonici y la Constitución Apostólica", y en la letra b) del citado artículo, "las leyes emanadas para la Ciudad del Vaticano por el Sumo Pontífice o de otra autoridad delegada por él", y con carácter supletorio las leyes civiles, comerciales, penales y procesales italianas vigentes y las locales de la provincia de Roma con las modificaciones exigidas por los principios generales del Derecho Canónico y por los preceptos del Derecho Divino.

En esta parte, es necesario recordar que con fecha 22 de febrero del año 2001, se procedió a modificar la Ley "Fundamental del Estado de la Ciudad del Vaticano", de fecha 7 de julio de 1929, promulgada por el Papa Pío XI, mencionada en el párrafo anterior en la letra b) del artículo $1^{\circ}$, señalándose en la introducción de la misma que, "el Sumo Pontífice tomando en consideración la necesidad de dar una forma sistemática y orgánica a los cambios, se ha procedido a su introducción en fases sucesivas en el ordenamiento jurídico de la Ciudad del Vaticano".

La Ley LXXI sobre las Fuentes de Derecho promulgada con fecha 1 de octubre del 2008 en el Acta Apostolicae Sedis por el Papa Benedicto XVI, sustituye la Ley promulgada el 7 de junio de 1929, después de los Pactos Lateranenses, cuya finalidad es continuar con la adecuación de la normativa del Estado de la Ciudad del Vaticano iniciada el año 2001 con la publicación de la Ley Fundamental, significando un paso más hacia la Constitución de un ordenamiento jurídico propio del Estado del Vaticano, cuya finalidad principal es ga- rantizar la independencia de la Santa Sede de cualquier poder político constituyendo así la estructura central de gobierno de una Iglesia universal.

Respecto a esta nueva Ley, podemos señalar que siguiendo la praxis legislativa postconciliar de reducir la normativa jurídica a lo esencial, se han reducido de 25 a 13 los artículos. En lo sustancial el cambio más destacado es la situación de privilegio que adquiere el Derecho Canónico entre las fuentes del Derecho, constituyéndose en el primer criterio de referencia para la hermenéutica de la ley, es así como el número $1^{\circ}$ del artículo $1^{\circ}$ al mencionar las fuentes principales del Derecho señala: "1. L'ordinamento giuridico vaticano riconosce nell'ordinamento canonico la prima fonte normativa e il primo criterio di riferimento interpretativo".

Esta principalidad se basa en la naturaleza instrumental del Estado Vaticano que existe como una garantía fundamental para la libertad de la Santa Sede y como un medio para asegurar la independencia real y visible del Papa en el ejercicio de sus funciones.

A este respecto, el Presidente de la Corte de Apelaciones del Estado de la Ciudad del Vaticano, don José María Serrano Ruiz ${ }^{5}$, señaló que, "esta materia había sido objeto de un amplio debate en la Comisión Preparatoria de la nueva ley y que permitía reconocer la naturaleza autónoma del derecho canónico".

De este modo la ley italiana pasará ahora a ser considerada como una fuente supletoria a un ordenamiento jurídico Vaticano que estará inspirado en el Derecho Canónico, esto es, se analizarán una a una las leyes italianas antes de que sean adoptadas por el Vaticano.

Es así como los números 1 y 2 del artículo $3^{\circ}$ de la Ley II sobre las Fuentes del Derecho, señalan al referirse a la recepción de la legislación italiana lo siguiente:

1. "Nelle materia alle quali non provvedono le fonti indicate nell'art. 1, si osservano, in via suppletiva e previo recepimento da parte della competente

\footnotetext{
5 Serrano Ruiz (2008).
} 
autorità vaticana, le leggi e gli altri atti normativi emanati nello Stato Italiano".

2. "Il recepimento è disposto purché i medesimi non risultino contrari ai precetti di diritto divino, né ai principi generali del diritto canonico, nonché alle norme dei Patti Lateranensi e successivi Accordi e sempre che, in relazione allo stato di fatto esistente nella Città del Vaticano, risultino ivi applicabili".

Se trata de una novedad que no puede ser ignorada pues la Ley precedente actuaba como una especie de recepción automática que se presumía como una regla y que por lo tanto solo era procedente rechazar una norma por vía de excepción por motivos de una radical incompatibilidad con leyes del ordenamiento Canónico o con tratados bilaterales; en consecuencia, la nueva normativa, variando sustancialmente el criterio anterior, prevé ahora la necesidad de una explícita recepción por parte de la autoridad competente.

Según lo señalado por José María Serrano Ruiz en el diario L'Obsservatore Romano, tres serían los motivos principales que justifican este cambio en la práctica: "las dimensiones excesivas del ordenamiento italiano, la inestabilidad del mismo por sus continuos cambios y finalmente el contraste, muchas veces objeto de gran resonancia pública de algunas leyes del Estado italiano con principios irrenunciables de la Iglesia Católica”.

\section{CONCLUSIÓN}

De lo expuesto sumariamente en los párrafos anteriores, se puede concluir que la finalidad de la nueva Ley sobre las Fuentes del Derecho es un paso más hacia la constitución de un Corpus Vaticanum, es decir, de un ordenamiento jurídico propio, coherente aunque obviamente reducido en comparación a los ordenamientos de las naciones, por la naturaleza específica del Estado de la Ciudad del Vaticano, cuya finalidad fundamental es garantizar la independencia de la Santa Sede del poder político de un Estado concreto, siendo estructura central de gobierno de la Iglesia universal.

Asimismo, la resolución del Estado Pontificio de dictar esta nueva ley, reemplazando a la que existía desde 1929, respondería a hechos como la legalización del divorcio o la decisión del Tribunal Supremo de Italia de permitir que se dejara de alimentar a la joven Eluana Englaro, en coma desde hacía 16 años, pero también se adelanta a futuras leyes que pudieren afectar a lo que tradicionalmente entendemos por familia.

En consecuencia, esta nueva Ley sobre las Fuentes del Derecho constituye un impulso adicional al ya dado en el año 2001 por la modificación de la Ley Fundamental de la Ciudad del Estado del Vaticano, al desarrollo de una legislación autónoma relativamente completa que pueda expresar los valores que animan a la comunidad vaticana. Ciertamente ha sido un proceso lento y articulado, como ha quedado de manifiesto en los párrafos anteriores, el cual comenzó en el año 1984 con la modificación del Tratado de Letrán.

\section{BIBLIOGRAFÍA CITADA}

Rodríguez de Cortázar, Joaquín (1924): "La Cuestión Romana”, La Gaceta Literaria.

Llanos Mancilla, Hugo (1980): "Teoría y Práctica del Derecho Internacional Público" (Santiago, Editorial Jurídica de Chile) Tomo II.

BenadaVA, Santiago (1976): Derecho Internacional Público (Santiago, Editorial Jurídica de Chile) 448 pp.

SERrano Ruiz, José María (2008): “Leggi italiane, lo Stato della cittá del Vaticano non le recibirá piú”, L'Osservatore Romano, 31 de diciembre de 2008. 